\title{
SUNAT PEREMPUAN DALAM PERSPEKTIF FIKIH
}

\author{
Afifi Fauzi Abbas \\ IAINBukittinggi,afififauriabbas@gmail.com \\ Mona Eliza \\ IAIN Bukittringgi,monaeliza@gmail.com
}

\begin{abstract}
In 2008 the MUI issued a fatwa related to female circumcision, namely fatwa number 94 "Fatwa on Probibition of Circumcision Against Women", which states that the legal status of female circumcision is makrumah, something that is considered good and recommended. In many studies it was found that female circumcision is just a tradition, not a religious order. In Indonesia, 28\% of female circumcision practices are only symbolic, $49 \%$ are done in the form of slicing or stabbing and $22 \%$ in the form of cutting. This means that $71 \%$ of the practice leads to endangering women, mainly because it is not carried out by medical personnel and uses tools that are not sterile. The Hanafi, Maliki and Hanbali schools place women's circumcision laws in the sunnah or makrumah / glory laws for women. The Syafii School believes that female circumcision is obligatory as a law for men. Although the various Islamic scholars have different opinions about the law of female circumcision, none of them probibits the practice of female circumcision.
\end{abstract}

Keywords: Khitan, Woman, Health, Fiqh.

\begin{abstract}
Abstrak
Tahun 2008 MUI mengeluarkan fatwa terkait dengan sunat perempuan, yaitu fatwa nomor 94 "Fatwa Pelarangan Kbitan Terbadap Perempuan", yang isinya menyatakan babwa status bukum khitan perempuan adalah makrumah, sesuatu yang dianggap baik dan dianjurkan. Dalam banyak kajian ditemukan bahwa khitan perempuan hanyalah sebuah tradisi, bukan perintah agama. Di Indonesia $28 \%$ praktek kbitan perempuan hanya dilakukan secara simbolis saja, 49\% dilakukan dalam bentuk pengirisan atau penusukan dan 22\% dalam bentuk pemotongan. Artinya $71 \%$ prakteknya mengarah kepada yang membahayakan kaum perempuan, terutama karena tidak dilakukan oleb tenaga medis dan menggunakan alat yang tidak steril. Mazhab Hanafi, Maliki dan Hanbali menempatkan bukum khitan perempuan pada bukum sunnah atau makrumab/kemuliaan bagi perempuan. Mazhab Syafii berpandangan bukum kbitan perempuan adalah wajib sebgaimana bukumnya bagi kaum laki-laki. Meskipun Ulama mazhab berbeda pendapat tentang hukum khitan perempuan, namun tak satupun di antara mereka yang melarang prak.tek khitan perempuan.
\end{abstract}

Kata Kunci: Khitan, Perempuan, Kesehatan, Fikih.

\section{PENDAHULUAN}

Sunat perempuan menjadi isu yang tak berkesudahan sejak dulu sampai hari ini, termasuk di Indonesia, baik pada tataran agama, sosial maupun kesehatan. Tahun 2008 MUI mengeluarkan fatwa terkait dengan sunat perempuan, yaitu fatwa nomor 94 "Fatwa Pelarangan Khitan Terhadap Perempuan", yang 
isinya menyatakan bahwa status hukum khitan perempuan adalah makrumah, sesuatu yang dianggap baik dan dianjurkan. ${ }^{1}$

Dalam banyak kajian ditemukan bahwa khitan perempuan hanyalah sebuah tradisi, bukan perintah agama. Di Indonesia $28 \%$ praktek khitan perempuan hanya dilakukan secara simbolis saja, $49 \%$ dilakukan dalam bentuk pengirisan atau penusukan dan 22\% dalam bentuk pemotongan. Artinya $71 \%$ prakteknya mengarah kepada yang membahayakan kaum perempuan, terutama karena tidak dilakukan oleh tenaga medis dan menggunakan alat yang tidak steril. ${ }^{2}$ Hanya saja tidak ditemukan komplikasi pada fisik maupun psikis, meskipun pada waktu dilakukan pengirisan atau pemotongan yang dikhitan merasakan sakit yang berlebihan. ${ }^{3}$

Muncul perbedaan pandangan di tengah tengah masyarakat, ada yang berpendapat Khitan perempuan itu banyak manfaatnya, tapi ada yang berpendapat khitan perempuan itu banyak mudaratnya. Untuk itu perlu dicarikan solusi pemecahannya yang berpihak kepada kemaslahatan perempuan, yaitu solusi fikih berdasarkan cara berfikir kontekstual dan toleran.

\section{PENGERTIAN KHITAN PEREMPUAN}

Setidaknya ada tiga definisi khitan perempuan yang kita temukan dalam kitab-kitab Fikih.

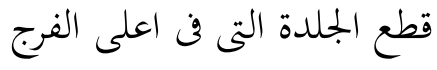

1 M. Asrorun Ni'am Sholeh, "Fatwa MUI Tentang Khitan Perempuan," AHKAM: Jurnal Ilmu Syariab 12, no. 2 (2012)

2 "Female Circumcision in Indonesia : To " Islamize " in Ceremony or Secrecy - Persée," accessed August 22, 2019, https://www.persee.fr/doc/arch_0044-

8613_1998_num_56_1_3495.

3 Tutung Nurdiyana, "SUNAT PEREMPUAN PADA MASYARAKAT BANJAR DI KOTA BANJARMASIN," KOMUNITAS: INTERNATIONAL JOURNAL OF INDONESLAN SOCIETY AND CULTURE 2, no. 2 (2010), https://doi.org/10.15294/komunitas.v2i2.2281.
Memotong kulit yang menutup klitoris

قطع الجلدة العالية المشرفة على فرجها Memotong bagian atas klitoris perempuan yang menonjol pada bagian vagina perempuan

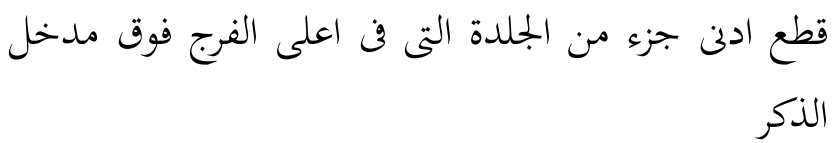

Memotong sedikit kulit klitoris bagian atas dari vagina tempat masuknya "zakar"

Yang menimbulkan masalah adalah lafaz yang digunakan dalam mendifinisikan khitan perempuan adalah قطع, bentuk lafaznya mujmal, sehimgga maknanya jadi luas, dapat dimaknai mulai dari menggores, melukai, mengiris dan memotong. Inilah yang menimbulkan beragamnya praktek khitan di kalangan masyarakat muslim. ${ }^{4}$ Maka diperlukan kejelian untuk memaknainya, makna mana yang lebih tepat untuk digunakan untuk konteks ke kinian. Kita harus responsive terhadap perubahan social yang terjadi dan akomodatif terhadap kemajuan hasi ilmu pengetahuan dan teknologi. Halaqah Nasional Ulama Pondok Pesantren se Indonesia di Bogor bulan Februari 2018 yang lalu lebih memilih makna yang soft. Yaitu menggores tanpa menyakiti dan tanpa memudaratkankan kepada perempuan.

\section{ALASAN KHITAN PEREMPUAN}

Hasil penelitian UNICEF (2010) menemukan sekurang-kurangnya ada 5 alasan mengapa masyarakat melakukan khitan perempuan:

Pertama, pertimbangan seksual, yaitu mengurangi/menurunkan hasrat seksual perempuaan (fakta/mitos?). Dalam masyarakat patriachi diyakini khitan perempuan dilakukan

4 Frisyahyani Nasution, "Khitan Perempuan (Rekonstruksi Pengetahuan dari Praktik Khitan Perempuan pada Keluarga Jawa Medan, Studi Kasus di Daerah Marelan)," January 30, 2010, http:// repository.usu.ac.id/handle/123456789/14924. 
supaya perempuan tidak menjadi genit dan hyper seks.

Kedua, pertimbangan sosial. Khitan perempuan sebagai inisiasi kedewasaan dan integrasi sosial bagi kaum perempuan.

Ketiga, pembersihan dan estetika. Karena alat genital perempuan itu kotor, khitan adalah untuk pembersihan, sehingga terbebas dari berbagai penyakit.

Keempat, alasan kesehatan, yaitu untuk meningkatkan kesuburan dan kelangsungan hidup anak

Kelima, pertimbangan agama, yaitu sebagai ekspesi keta'atan beragama.

\section{PRAKTEK KHITAN PEREMPUAN}

Organisasi Kesehatan Dunia (WHO) 2008 membagi praktek khitan perempuan di dunia dalam 4 klasifikasi:

Tipe I; Clitoridictomy, yaitu pembuangan sebagian maupun seluruh klitoris dan atau tudung klitoris. Tipe ini terbagi dua; 1. Pembuangan dilakukan sebatas pada tudung klitoris. 2. Pembuangan mencakup tudung dan klitorisnya sekaligus.

Tipe II; Excision, pembuangan sebagian maupun seluruh klitoris berikut labia minora, baik dengan pengirisan maupun tanpa labia majora. Tipe ini ada 3 variasi: 1. Pembuangan sampai sebatas labia minora. 2. Pembuangan mencakup sebagian maupun seluruh klitoris dan labia minora. 3. Pembuangan sebagian atau seluruh klitoris, labia minora dan labia majora.

Tipe III; Infibulation, yaitu cara penyempitan lubang vagina dengan cara memotong labia minora dan atau labia majora, baik dengan pengirisan ataupun tanpa pengirisan klitoris. Tipe III ini ada 2 model; 1. Hanya membuang labia minora. 2. Dengan membuang labia majora.

Tipe IV; Unclassified, yaitu praktek selain I, II dan III, ada dalam bentuk penusukan, penggoresan, pengirisan dan pembakaran jaringan alat genital perempuan yang membahayakan dengan tujuan non medis. ${ }^{5}$

Di Indonesia yang diperbolehkan adalah diluar keempat tipe tsb. PERMENKES No. 1636 th 2010 pasal 1 ayat 1 menjelaskan bahwa khitan perempuan itu adalah menggores kulit yang menutup yang menutupi bagian depan klitoris tanpa melukaimya.

\section{EFEK NEGATIF KHITAN PEREMPUAN}

Laporan WHO (2010) menyatakan bahwa perempuan yang melakukan khitan berpotensi; mengalami sakit yang parah, pendarahan, tetanus, infeksi bakteri, urin yang tidak lancar, luka terbuka, demam, dan infeksi saluran kemih. ${ }^{6}$

Kerugiannya tidak hanya berjangka pendek, tetapi bisa juga berjangka panjang seperti pemunculan kista, mengalami ketidak suburan, konplikasi dan kematian bayi. Secara psikis efek negatifnya adalah hilangnya rasa percaya diri, menurunnya kebugaran fisik, trauma bahkan depresi.

\section{DALIL ATAU ARGUMENTASI KHITAN PEREMPUAN.}

Alquran surat al-Nabl ayat 123.

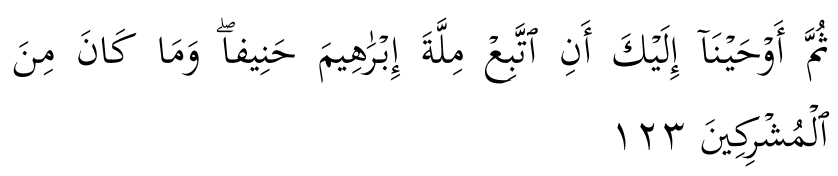

Kemudian Kami wabyukan kepadamu (Muhammad): "Ikutilah agama Ibrahim seorang yang hanif" dan

${ }^{5}$ Muhammad Sauki, "Khitan Perempuan Perspektif Hadis Dan Sirkumsisi Perempuan Menurut WHO," July 28, 2011,

http://repository.uinjkt.ac.id/dspace/handle/123456789/471 6.

6 "Female Circumcision: Toward an Inclusive Practice of Care: Health Care for Women International: Vol 31, No 8," accessed August 22, 2019, https://www.tandfonline.com/doi/abs/10.1080/07399332.2 010.490313 . 
bukanlah dia termasuk orang-orang yang mempersekutukan Tuhan

Ayat ini menjelaskan supaya kaum muslimin mengikuti ajaran Nabi Ibrahim a.s., termasuk khitan laki-laki maupun perempuan. Dalam hadis yang diriwayatkan oleh Bukhari dan Muslim dinyatakan bahwa Nabi Ibrahim memang berkhitan seperti dijelaskan oleh hadis berikut:

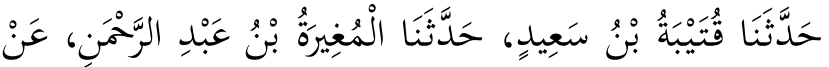

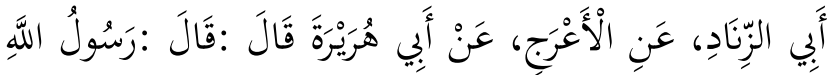

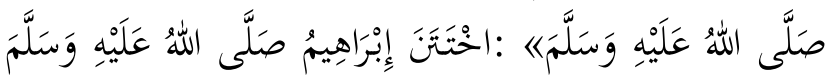

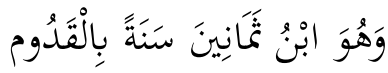

Diriwayatkan dari Abu Hurairah r.a., beliau mengatakan babwa Nabi saw. Bersabda : Nabi Ibrabim a.s. melakukan khitan dengan kapak saat berusia 80 tabun.

\section{Hadis Ummu Athiyyah.}

Ada tiga versi (matan) hadis Ummu Athiyah yng membicarakan khitan yang sering dijadikan hujjah ketika orang membicarakan khitan perempuan, di antaranya:

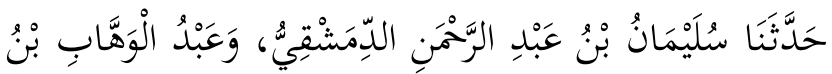

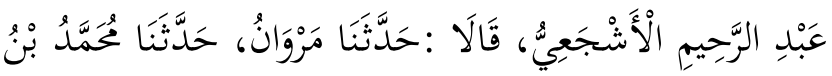

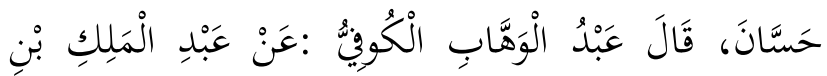

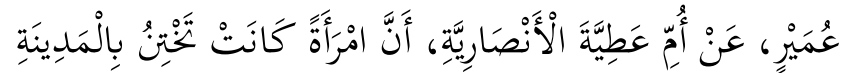

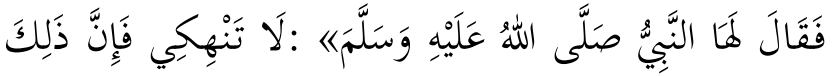

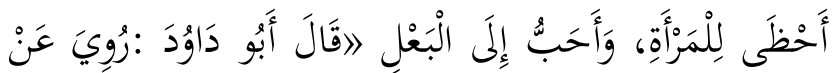
عُبَيْدِ اللَّهِ بْنِ عَمْرِوِ عَنْ ص [369:عَبْدِ الْمَلِكِك، بِعَعْنَاهُ

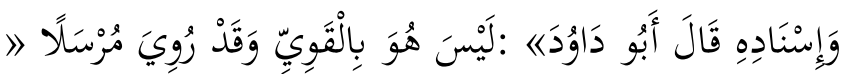

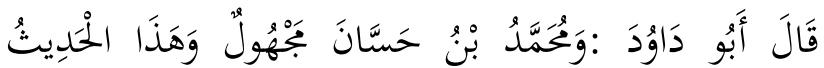
ضَعِيفن
Diriwayatkan dari Ummu Athiyyah, bahwa seorang perempuan akan melakukan khitan, maka Nabi bersabda : Janganlah kau lakukan pemotongan secara berlebihan karena hal itu lebih nikmat buat perempuan dan lebih disukai oleh suami (HR. Abu Daud, dan Baihaqy)

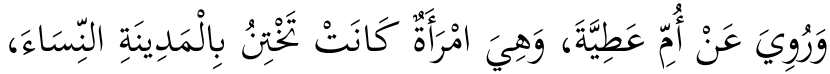

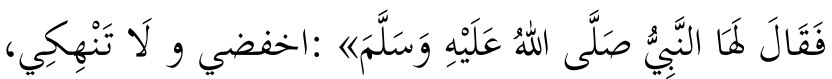

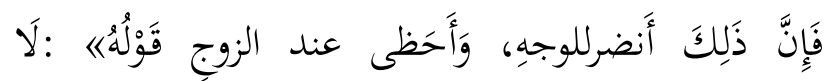

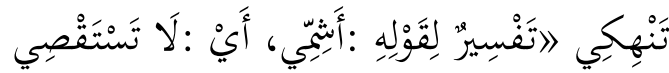
Diriwayatkan dari Umun Athiyyah, dia seorang pengkhitan perempuan di madinah. Nabi pernah berkata padanya : Jika kamu mengkhitan perempuan janganlah memotongnya secara berlebihan, karena yang demikian itu membuat cahaya bagi wajah perempuan dan nikmat bagi suami. (HR. Baihaqy dan Thabraniy).

عن انس بن مالك ان النى ص.م .قال لام عطية ختانة بالمدينة اذا خفضت فأشيمي ولا تنهكي فانه اسرى للوجه واحظى عند الزوج

Diriwayatkan dari Anas bin Malik bahwasanya Nabi saw. Berkata kepada Umu Athiyyah seorang pengkhitan perempuan di Madinah : Apabila engkau mengkhitan perempuan maka potonglah, tapi jangan berlebiban, karena hal tersebut membuat wajah perempuan berbinar dan disukai oleh suami. (HR.Thabraniy)

Hadis Syaddad bin Aus

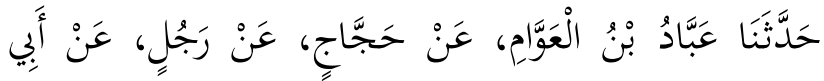
الْمَلِيحِ، عَنْ شَدَّادِ بْنِ أَوْسِ، قَالَ :قَالَ رَسُولُ اللَّهِ صَلَّلى اللَُّ

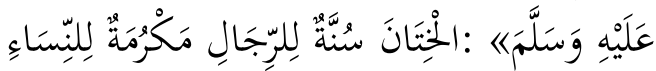

Diriwayatkan dari Syaddad bin Aws dia berkata : Nabin saw. telah bersabda: kbitan itu sunnah bukumnya bagi laki-laki dan makrumah (penghormatan) bagi perempuan. (HR.Baihaqy, Thabraniy dan Ibn Abi Syaibab)

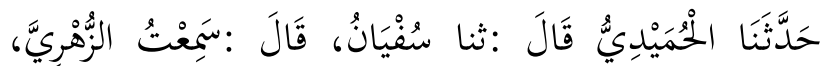

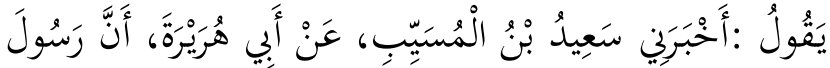




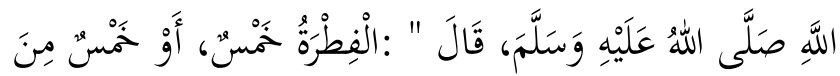

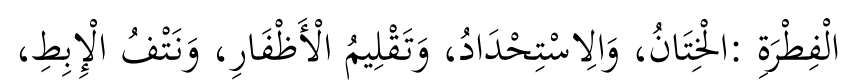
وَقَصُّ الشَّارِبِ

Diriwayatkan dari Abu Hurairah babwa Nabi saw. Telab bersabda : Ada lima perbuatan yang dikategorikan sebagai fitrah yaitu : kbitan, mencukur bulu kemaluan, mencabut bulu ketiak, memotong kumis dan memotong kuku. (HR. Muslim)

\section{Hadis Aisyah}

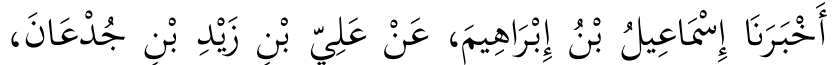

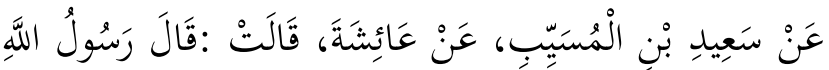

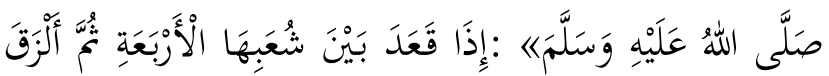

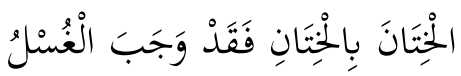

Diriwayatkan dari Aisyah ra. Dia mengatakan bahwa Rasulullah saw. Telah bersabda: Apabila suami duduk. diantara empat percabangan istrinya, kemudian kemaluan suami telab menyintub kemaluan istrinya, maka wajiblah mandi besar. (HR.Muslim).

\section{PENDAPAT ULAMA TENTANG KHITAN PEREMPUAN}

Mazhab Hanafi, Maliki dan Hanbali menempatkan hukum khitan perempuan pada hukum sunnah atau makrumah/ kemuliaan bagi perempuan.

Mazhab Syafii berpandangan hukum khitan perempuan adalah wajib sebgaimana hukumnya bagi kaum laki-laki.

Meskipun Ulama mazhab berbeda pendapat tentang hukum khitan perempuan, namun tak satupun di antara mereka yang melarang praktek khitan perempuan. Begitupun dengan ulama-ulama kontemporer juga terdapat perbedaan pendapat. Abdullah bin Baz, Jadul Haq menghukuminya dengan sunnah. Yusuf Qaradlawiy menghukuminya dengan mubah. Sedangkan Syaltut mengatakan khitan perempuan taka da kaitannya dengan ajaran agama, itu hanyalah semata- mata budaya yang mengandung kemaslahatan bagi lakilaki sedangkan bagi perempuan mengandung kemudaratan.

\section{PENUTUP}

Bila kita cermati lebih dalam apa yang telah diuraikan di atas maka ada beberapa hal yang dapat kita simpulkan.

Karena tak satupun dalil-dalil tentang khitan perempuan sampai pada tingkat (darajatul wudlub) yang wadlib dilalah, maka sangat sulit bagi kita untuk menerima hukum wajib ataupun sunnah. Ayat yang diajadika dalil bentuk lafaznya mujmal, dan hadis-hadisnya pada umumnya dhaif. Kalaupun ada yang shahih hadis tersebut tidak bicara tentang khitannya.

Karena praktek khitan perempuan itu mudaratnya lebih besar dari manfaatnya maka menghindarinya lebih utama dari pasa mengerjakannya.

Kalaupun akan tetap dilakukan khitan perempuan maka harus dipilih cara yang paling soft, yaitu sekedar menggores genital perempuan tanpa melukai dan menyakitinya dan dilakukan oleh tenaga trampil/medis dan menggunakan alat-alat yg steril.

Dengan demikian hukumnya hanya sampai pada tingkat makrumah saja.

\section{DAFTAR KEPUSTAKAAN}

"Female Circumcision in Indonesia : To " Islamize " in Ceremony or Secrecy Persée." Accessed August 22, 2019. https://www.persee.fr/doc/arch_00448613_1998_num_56_1_3495.

"Female Circumcision: Toward an Inclusive Practice of Care: Health Care for Women International: Vol 31, No 8." Accessed August 22, 2019. https://www.tandfonline.com/doi/abs/10. 1080/07399332.2010.490313.

Nasution, Frisyahyani. "Khitan Perempuan (Rekonstruksi Pengetahuan dari Praktik Khitan Perempuan pada Keluarga Jawa Medan, Studi Kasus di Daerah Marelan)," 
January 30, 2010. http://repository.usu.ac.id/handle/123456 $789 / 14924$.

Ni'am Sholeh, M. Asrorun. "Fatwa MUI Tentang Khitan Perempuan." AHKAM: Jurnal Ilmu Syariab 12, no. 2 (2012).

Nurdiyana, Tutung. "SUNAT PEREMPUAN PADA MASYARAKAT BANJAR DI KOTA BANJARMASIN." KOMUNITAS: INTERNATIONAL JOURNAL OF INDONESLAN SOCIETY AND CULTURE 2, no. 2 (2010). https://doi.org/10.15294/komunitas.v2i2.2 281.

Sauki, Muhammad. "Khitan Perempuan Perspektif Hadis Dan Sirkumsisi Perempuan Menurut WHO," July 28, 2011. http://repository.uinjkt.ac.id/dspace/handl e/123456789/4716. 